\title{
Development of Smart Automated Irrigation System
}

\author{
Sirisha Adamala ${ }^{1}$, Krishna Reddy $\mathrm{YV}^{2}$
}

\author{
${ }^{1}$ Assistant Professor, Department of Applied Engineering, Vignan's Foundation for Science, Technology and Research \\ University (VFSTRU), Vadlamudi (Guntur), Andhra Pradesh, India \\ ${ }^{2}$ Research Assistant, Central Research Institute for Dryland Agriculture (CRIDA), Hyderabad, Telangana, India
}

\begin{abstract}
This study is designed to develop an automatic irrigation system that switches (ON/OFF) a pump motor by sensing the moisture content of the soil using wireless technology. Through GSM Modem, the sensed moisture content data will be sent as an SMS to the user. The project uses 8051 series microcontroller, which is programmed to receive the input signal of varying moistures of the soil through sensors. This is achieved by using an op-amp as comparator which acts as interface between the sensing device and the microcontroller. Once the controller receives the signal, it generates an output that drives a relay for operating the water pump. It also sends an SMS to the concerned number using GSM modem. An LCD display is also interfaced to the microcontroller to display the status of the soil and water pump ON/Off condition. The sensing arrangement is made using two stiff metallic rods inserted to the agricultural field required to be in control. Connections from the metallic rods are interfaced to the control unit. This concept can also be enhanced by integrating XBEE/Bluetooth technology, such that whenever the water pump switches ON/OFF, the information is sent to a smart mobile phone or XBEE transceiver module regarding the status of the pump.
\end{abstract}

Keywords-Automation, Irrigation, Micro-controller, Bluetooth, GSM Module.

\section{INTRODUCTION}

Water is a very precious resource and must be properly utilized. Agriculture is one of those areas which consume a lot of water. Irrigation is a time consuming process and must be done on a timely basis. The aim of this study is to develop an auto irrigation system which measures the moisture of the soil and automatically turns on or off the water supply system. The project requires very less human involvement once installed. The circuit is based on PIC microcontroller and also a soil moisture sensor. A properly configured soil moisture sensor can save up to 60 percent of water used in irrigation. Irrigation system uses valves to turn irrigation $\mathrm{ON}$ and OFF. These valves may be easily automated by using controllers and solenoids. Automating farm or nursery irrigation allows farmers to apply the right amount of water at the right time, regardless of the availability of labor to turn valves on and off. In addition, farmers using automation equipment are able to reduce runoff from over watering saturated soils, avoid irrigating at the wrong time of day, which will improve crop performance by ensuring adequate water and nutrients when needed. It also helps in time saving, removal of human error in adjusting available soil moisture levels and to maximize their net profits. A lot of research has been done by many authors (Dukes et al. 2003; Suriyachai et al. 2012; Smajstrla and Locascio, 1996; Phene and Howell, 1984; Nogueira et al. 2003; Dursun and Ozden, 2011; Prathyusha and Suman, 2012; Gracon et al. 2010; Dukes and Scholberg, 2005).

Irrigation of plants is usually a very time consuming activity; to be done in a reasonable amount of time, it requires a large amount of human resources. Traditionally, all the steps were executed by humans. Now a days, some systems use technology to reduce the number of workers or the time required to water the plants. With such systems, the control is very limited, and many resources are still wasted. Water is one of these resources that are used excessively. Flood irrigation is one method used to water plants. This method represents massive losses since the amount of water given is in excess of plants need. The contemporary perception on of water is that of a free, renewable resource that can be used in abundance. However, this is not reality; in some parts of India, water consumption is taxed. It is therefore, reasonable to assume that it will soon become a very expensive resource everywhere. In addition to excess cost of water labour is becoming more and more expensive. As a result, if no effort is in invested in optimizing these resources, there will be more money involved in this process. Technology is probably a solution to reduce the costs and prevent loss of resources. The objective of this study is to design a small scale automated irrigation system that would use water in a more efficient way, in order to prevent water loss and minimize the cost of labour.

\section{MATERIALS AND METHODS}

This study proposed an embedded system for automatic control of irrigation (Fig. 1). This project has wireless 
sensor network for real-time sensing and control of an irrigation system. This system provides uniform and required level of water for the agricultural farm and it avoids water wastage. When the condition of water in the agricultural farm is abnormal then the system automatically switches ON the motor. When the water level reaches normal level the motor automatically switch
OFF. In this project we are interfacing microcontroller through temperature sensor, humidity sensor and also interfacing to GSM through wireless network. In this we set specified values of temperature, humidity and the conditioned is uniformly monitored by any programming language.

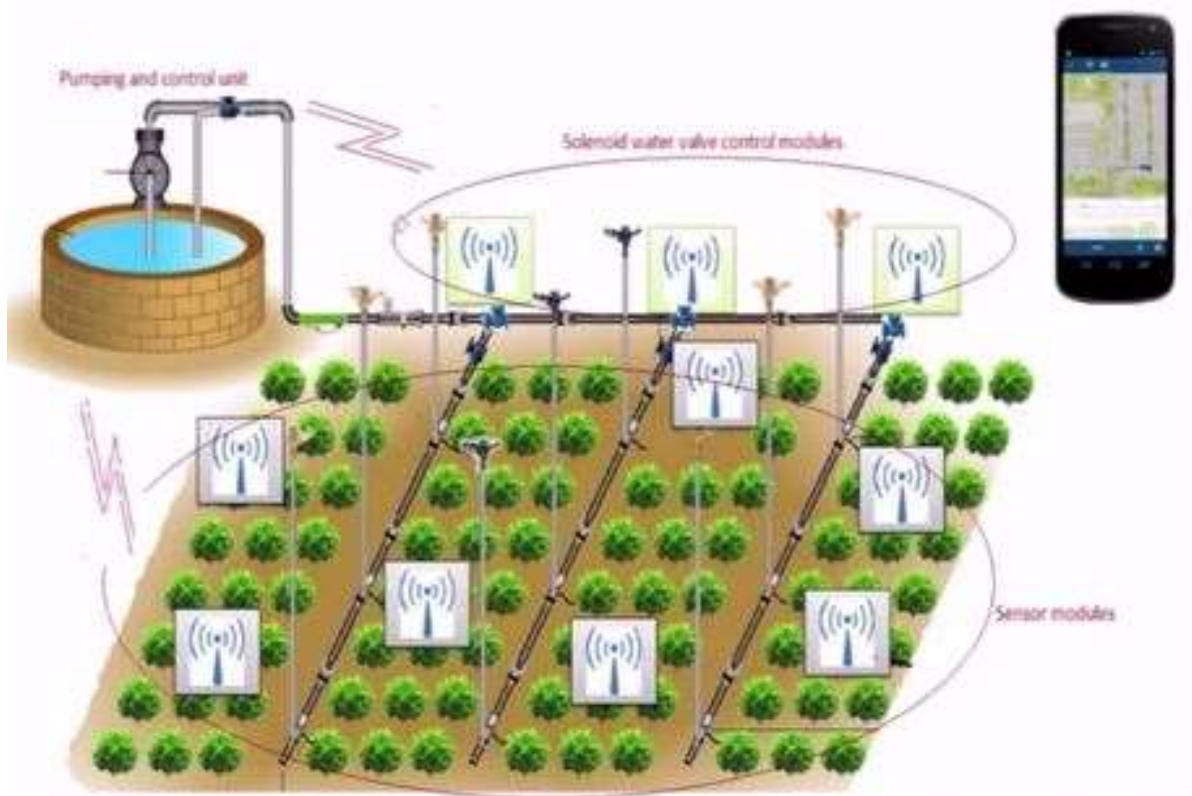

Fig. 1 Automated Irrigation System

The various equipments needed to develop an automated smart irrigation system are listed in Table 1. Hardware requirements are Microcontrollers (AT89C52/S52), opamp, Max232, GSM modem, Crystal oscillator,
Switch, LED, Resistors, Capacitors, voltage Regulator, relay driver (ULN2003), relay, DB9 connector. Software requirements are Keil compiler and programming language compiled is embedded C (Or) Assembly.

Table.1.: Detailed components required for designing a smart irrigation system

\begin{tabular}{|l|l|}
\hline \multicolumn{1}{|c|}{ Component Name } & \multicolumn{1}{c|}{ Configuration } \\
\hline Resistors & $330 \mathrm{R}, 1 \mathrm{~K}, 2.2 \mathrm{~K}, 4.7 \mathrm{~K}, 10 \mathrm{~K}$ and 10K Preset \\
\hline Capacitors & $1000 \mathrm{uF} / 35 \mathrm{~V}, 10 \mathrm{uF} / 63 \mathrm{~V}, 1 \mathrm{uF} / 63 \mathrm{~V}, 33 \mathrm{pF}$ Ceramic \\
\hline Integrated Circuits & 7805,7809, AT89S52, MAX232, LM358 \\
\hline IC Bases & $40-\mathrm{PIN}$ BASE, 16-PIN BASE, 08-PIN BASE \\
\hline Diodes & $1 \mathrm{~N} 4007$ \\
\hline BC547 & \\
\hline CRYSTAL & $11.0592 \mathrm{MHz}$ \\
\hline DB9 Male Connector PCB Mounted & \\
\hline Straight DB9 Cord & \\
\hline LCD & $16 \times 2$ \\
\hline LED-RED & \\
\hline 12V Relay & \\
\hline 2 PIN Push Button & \\
\hline Power Cord & \\
\hline Transformer & $0-12 \mathrm{~V}$ \\
\hline Female Burge & $0-12 \mathrm{~V}$ \\
\hline
\end{tabular}




\begin{tabular}{|l|l|}
\hline Male Burge (Included With LCD) & 16 PIN \\
\hline PCB Connector & 2-PIN \\
\hline Sensor Strip & \\
\hline Male Relement & 2-PIN \\
\hline Male Burge & 2-PIN \\
\hline $\begin{array}{l}\text { Female Relement (Transformer \& } \\
\text { GSM MODEM) }\end{array}$ & 2-PIN \\
\hline GSM MODEM & \\
\hline DC Pin & \\
\hline Heat Sink & \\
\hline Screw Nut For Heat-Sink & \\
\hline Submersible Pump & \\
\hline Copper Wire for Load & \\
\hline Plain PCB & \\
\hline Soldering LED & \\
\hline Connecting Wire & \\
\hline
\end{tabular}

The entire field is first divided into small sections such that each section should contain one moisture sensor (Fig. 2). These sensors are buried in the ground at required depth. Once the soil has reached desired moisture level the sensors send a signal to the micro controller to turn on the relays (Fig. 3), which control the motor. In this system, automated irrigation mechanism turns the pumping motor $\mathrm{ON}$ and OFF on detecting the dampness content of the soil. In the domain of farming, utilization of appropriate means of irrigation is significant. The benefit of employing these techniques is to decrease human interference. This automated irrigation project, the soil sensor senses the moisture content by giving input signal to an Arduino board which operates on 8051 series micro-controller (Fig. 4), is programmed to collect the input signal of changeable dampness circumstances of the earth via dampness detecting system.

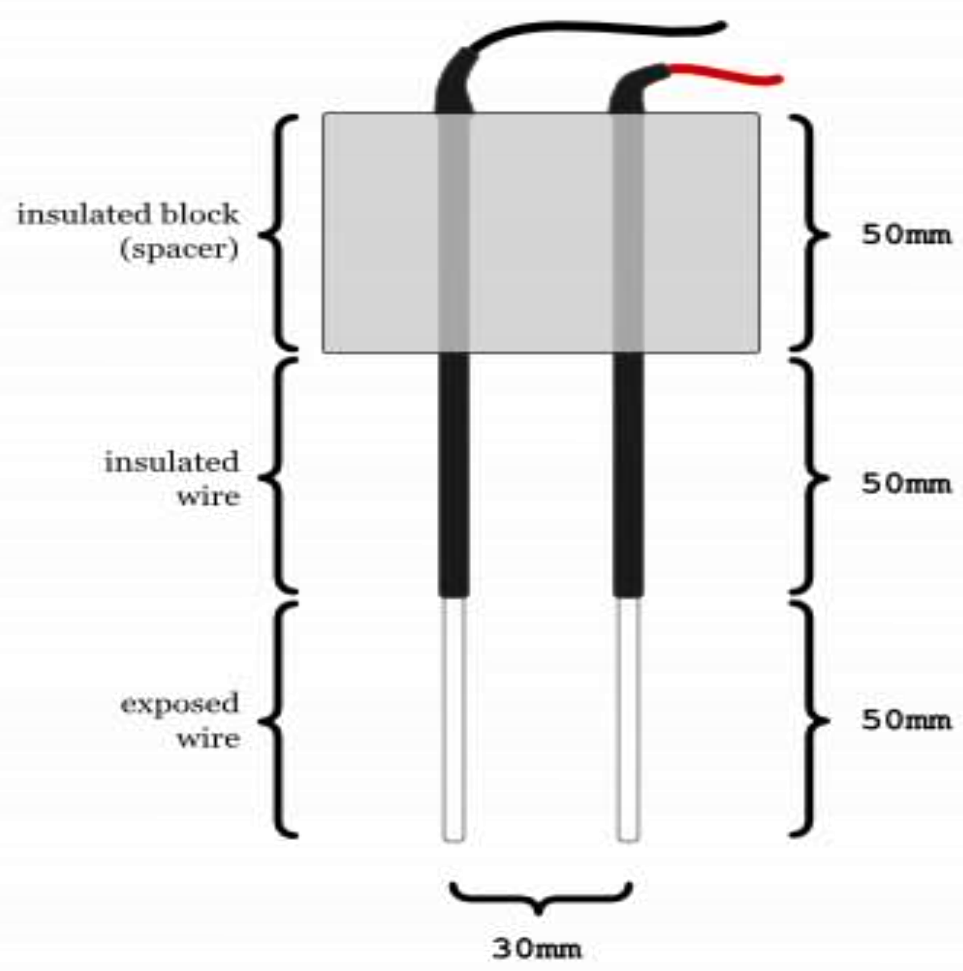

Fig. 2 Soil moisture sensor 


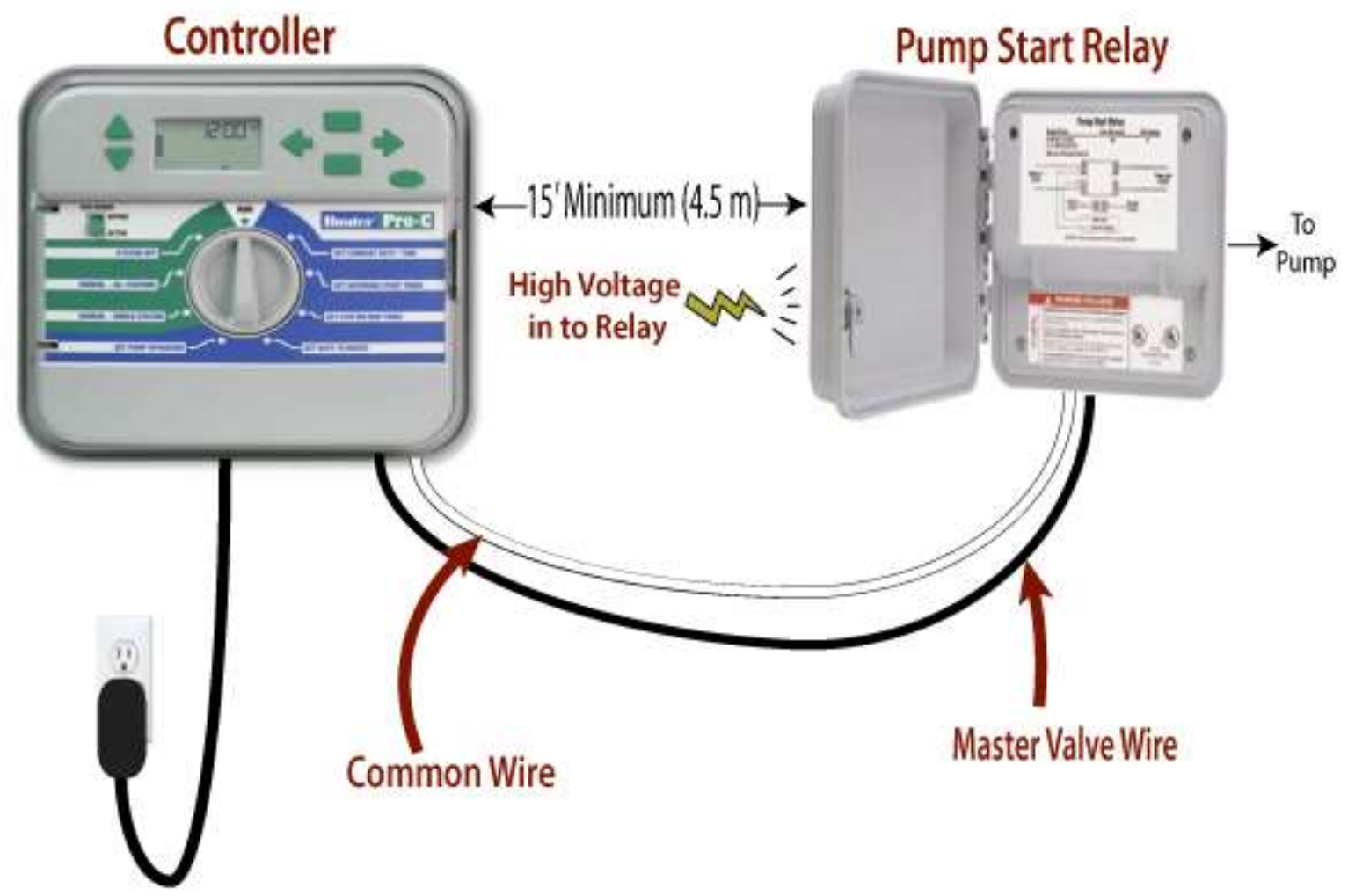

Fig. 3: Op-amp Relay

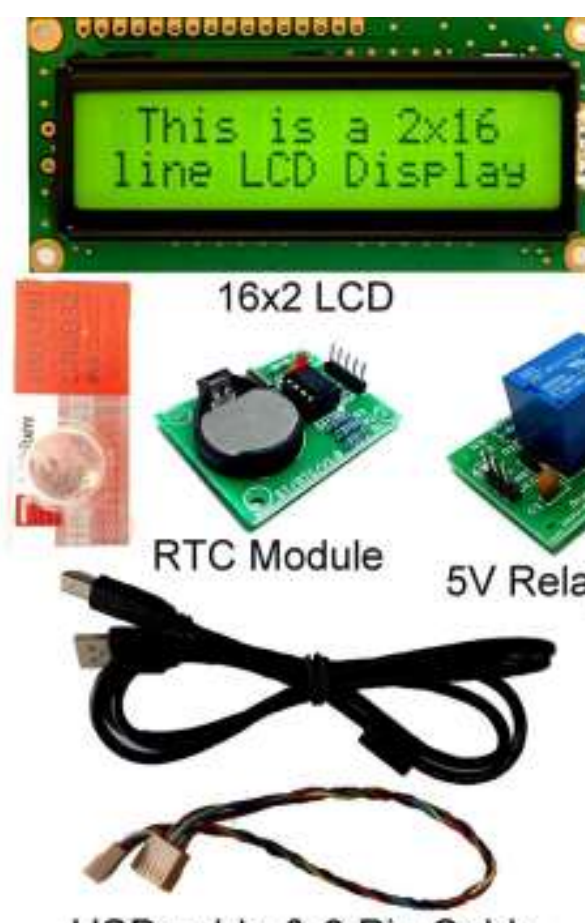

USB cable \& 6 Pin Cable
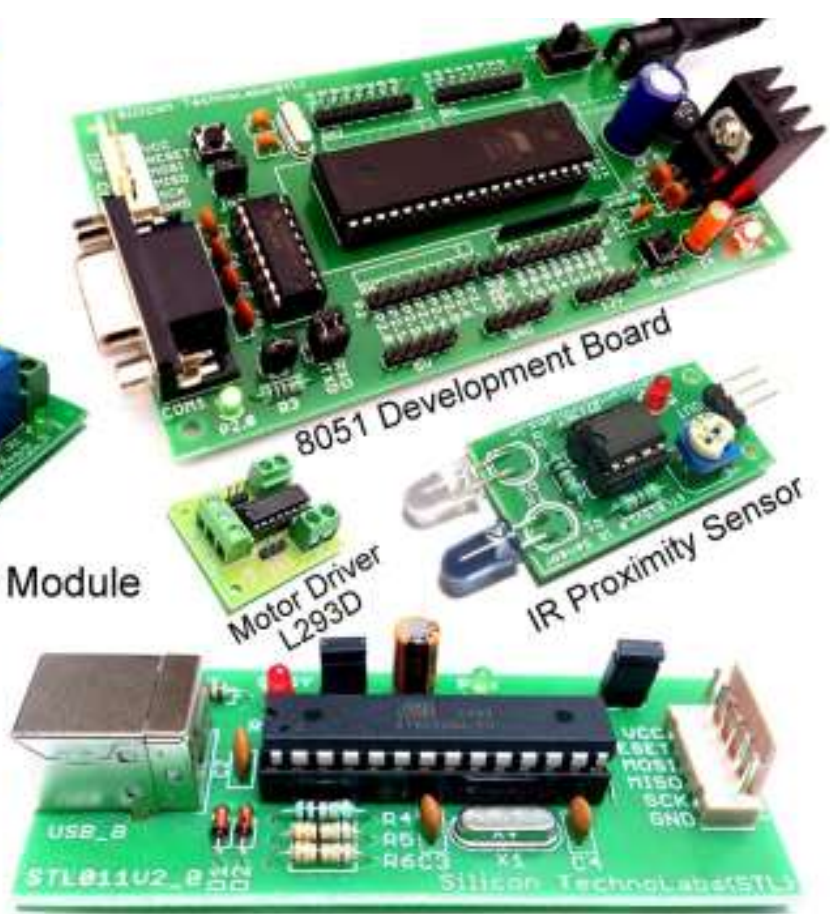

8051 \& AVR USB ISP Programmer

Fig. 4: 8051 Microcontroller

The idea of the study is to implement an automatic irrigation system by sensing the moisture of the soil. The working of the circuit is shown in Fig. 5. The microcontroller used in the project is 8-bit microcontroller. The main functions of the microcontroller are reading the values from the soil moisture sensor, displaying appropriate messages on the
LCD and controlling the relay to the motor. The soil moisture sensor is inserted in the soil. Depending on the quality of the sensor, it must be inserted near the roots of the plant. The soil moisture sensor measures the conductivity of the soil. Wet soil will be more conductive than dry soil. The soil moisture sensor module has a comparator in it. The voltage from the prongs and the 
predefined voltage are compared and the output of the comparator is high only when the soil condition is dry. This output from the soil moisture sensor is given to the analogue input pin of the microcontroller. The microcontroller continuously monitors the analogue input pin. When the moisture in the soil is above the threshold, the microcontroller displays a message mentioning the same and the motor is off. When the output from the soil moisture sensor is high i.e. the moisture of the soil is less. This will trigger the microcontroller and displays an appropriate message on the LCD and the output of the microcontroller, which is connected to the base of the transistor, is high. When the transistor is turned on, the relay coil gets energized and turns on the motor. The LED is also turned on and acts as an indicator. When the moisture of the soil reaches the threshold value, the output of the soil moisture sensor is low and the motor is turned off. The system is also designed to warn when the moisture is very high than the threshold and the soil is too wet, which is dangerous for the plant.

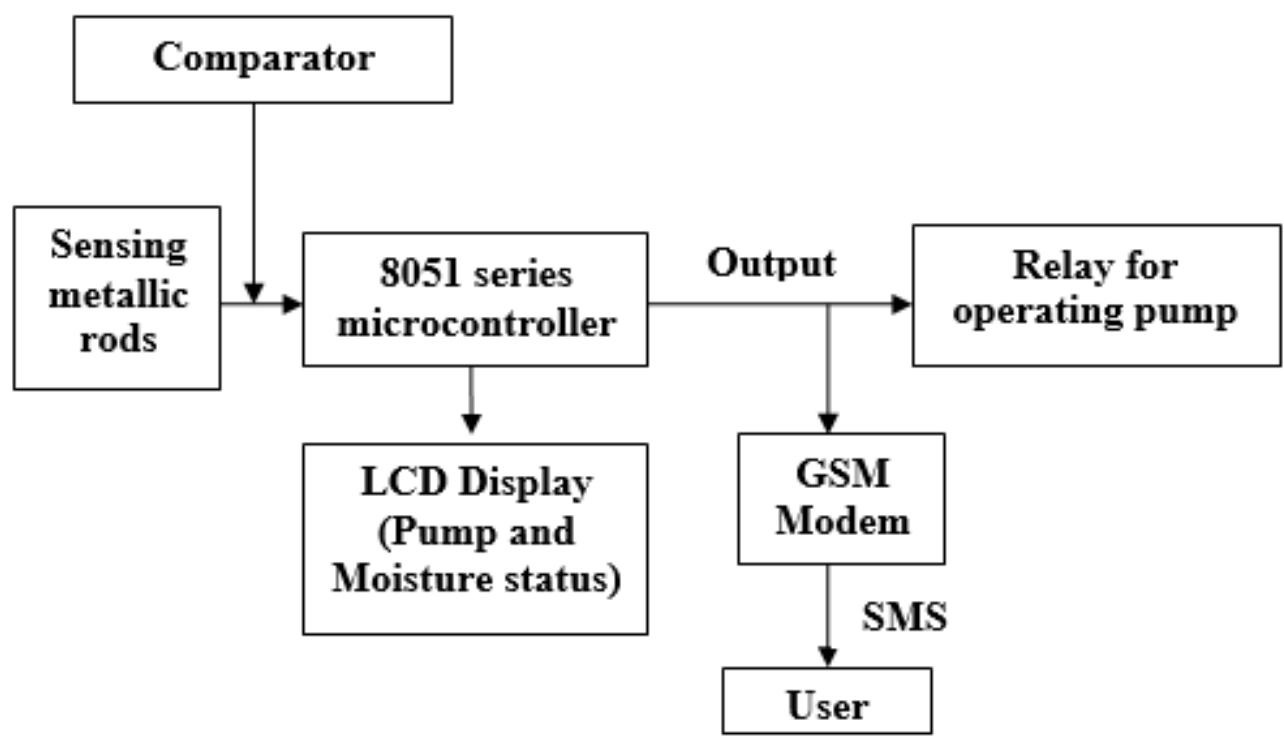

Fig. 6: Methodology diagram

Fig. 7 shows Microcontroller based irrigation system, which proves to be a real time feedback control system that monitors and controls all the activities of irrigation system efficiently.

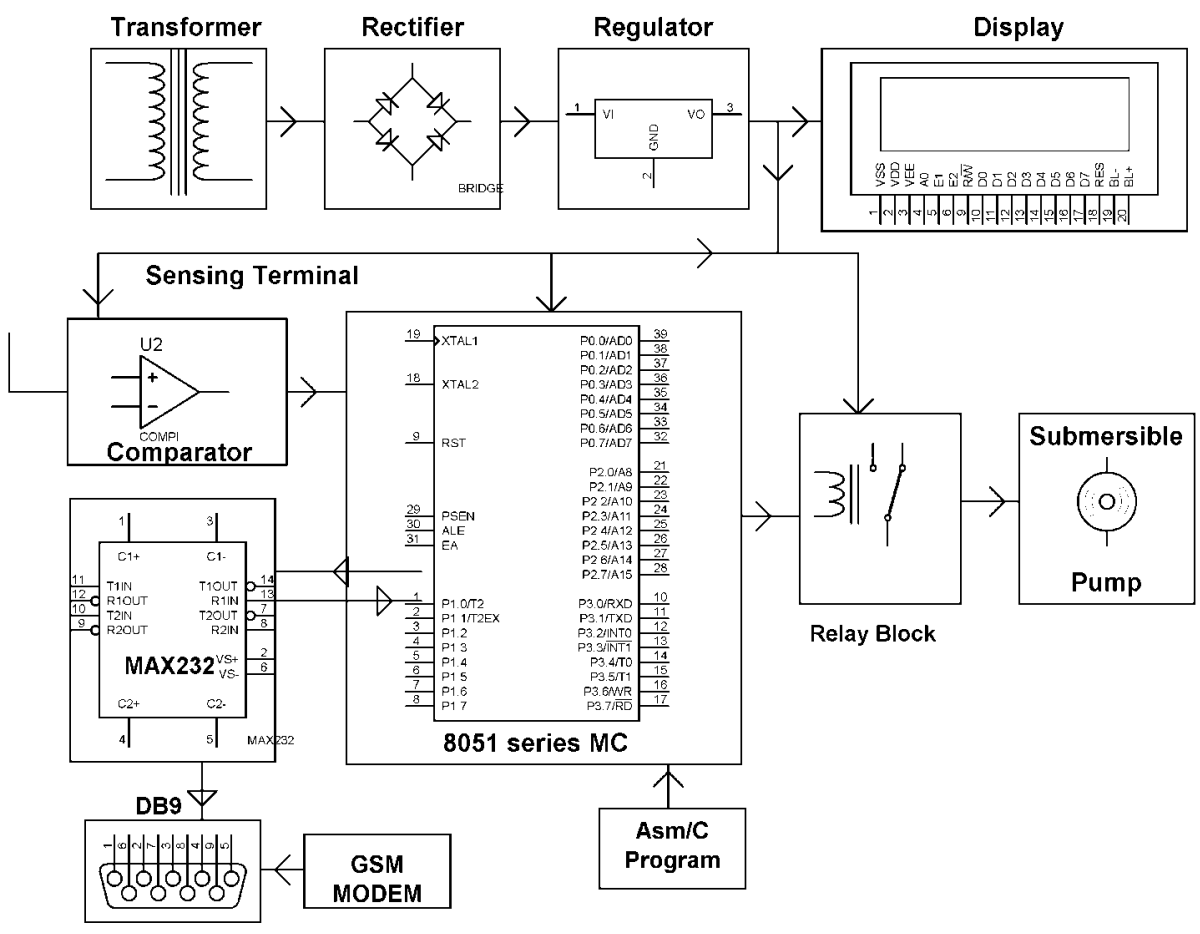

Fig. 7: Block diagram of the system 
III. RESULTS AND DISCUSSION

Irrigation becomes easy, accurate and practical with the idea above shared and can be implemented in agricultural fields in future to promote agriculture to next level. The output from moisture sensor and level system plays major role in producing the output. The chosen approach is expected to yield the following results.

- Reduced labour

- Reduced monitoring

- Decrease in water input

- Low maintenance

- Low power consumption

The advantage of using this method is to reduce human intervention and to ensure proper irrigation.

- Minimizes water waste and improves plant growth.

- This system is designed to work automatically and hence, there is no need for any human intervention.

\section{CONCLUSIONS}

The primary applications for this project are for farmers and gardeners who do not have enough time to water their crops/plants. It also covers those farmers who waste of water during irrigation. The project can be extended to greenhouses where manual supervision is far and few in between. The principle can be extended to create fully automated farmlands. Combined with the principle of rain water harvesting, it could lead to huge water savings if applied in the right manner. In agricultural lands with severe shortage of rainfall, this model can be successfully applied to achieve great results with most types of soil.

\section{REFERENCES}

[1] Dukes, M. D. and Scholberg, J. M. (2005). Soil moisture controlled subsurface drip irrigation on sandy soils. Applied Engineering in Agriculture 21(1): 89-101.

[2] Dukes, M. D., Simonne, E. H., Davis, W. E., Studstill, D. W., Hochmuth, R. (2003). Effect of sensor-based high frequency irrigation on bell pepper yield and water use. Proceedings of $2^{\text {nd }}$ International Conference on Irrigation and Drainage, May 12-15. Phoenix, AZ. pp. 665-674.

[3] Dursun, M. and Ozden, S. (2011). A wireless application of drip irrigation automation supported by soil moisture sensors. Scientific Research and Essays, 6(7), pp. 1573-1582.

[4] Gracon H. E. L. de Lima, Lenardo C. e Silva, and Pedro F. R. Neto (2010). WSN as a tool for supporting agriculture in the precision irrigation, Sixth International Conference on Networking and Services, 137-142.
[5] Nogueira, L. C., Dukes, M. D., Haman, D. Z., Cholberg, J. M., Cornejo, C. (2003). Data acquisition and irrigation controller based on CR10X datalogger and TDR sensor. Proceedings Soil and Crop Science Society of Florida 2002, 62:38-46.

[6] Phene, C. J. and Howell, T. A. (1984). Soil sensor control of high frequency irrigation systems. Transactions ASAE, 27(2):392-396.

[7] Prathyusha, K. and Suman, M. C. (2012). Design of embedded systems for the automation of drip irrigation. IJAIEM 1(2).

[8] Smajstrla, A. G. and Locascio, S. J. (1996). Tensiometer-controlled drip irrigation scheduling of tomato. Applied Engineering in Agriculture, 12(3):315-319.

[9] Suriyachai, P., Roedig, U. and Scott, A. (2012). A survey of MAC protocols for mission-critical applications in wireless sensor networks. Commun. Surveys Tuts., 14(2), 240-264. 